\title{
Emotional finance: as a new approach to understanding the markets
}

\author{
Asiye Nur DUMANLI $^{1}$ (D) Selim AREN ${ }^{2}$ \\ 1 Merkezi Kayıt Kuruluşu A.Ş., Istanbul/TURKEY, e-mail: asiye.nur.zengin@gmail.com \\ 2 Prof. Dr. Yıldız Technical University, Faculty of Economics and Administrative Sciences, Department of Business Administration, Istanbul/TURKEY,e-mail: \\ E-mail: saren@yildiz.edu.tr
}

\section{Abstract}

The emotional finance theory was developed as an alternative to the mainstream theories which claim that markets are driven by investors' conscious processes. Based on psychoanalysis, it searches the role of both conscious and unconscious processes in investment decisions. It offers new explanations regarding the causes and forecasting of the crises and bubbles that have been experienced frequently especially since the 2000s. In this framework, it makes use of concepts such as narrative, group feel, states of mind, and phantastic object, which have not been previously included in finance studies to date. This study represents the most comprehensive literature study carried out in the field of emotional finance to date. It analyses and models the fundamental components of the theory in the context of their determinants and effects. It offers findings to help market regulators, fund managers and investors understand the bubbles that occur in the markets.

Keywords: Emotional Finance, Narrative, Group Feel, States of Mind, Phantastic Object

Jel codes: G40, G41, D91

Citation/Atıf: DUMANLI. A. N. \& AREN.S., (2021). Emotional finance: as a new approach to understanding the markets. Journal of Life Economics. 8(2):173-183, DOI: $10.15637 /$ jlecon.8.2.03

Corresponding Author/ Sorumlu Yazar: Asiye Nur Dumanlı

E-mail: asiye.nur.zengin@gmail.com
Bu derginin içeriği Creative Commons Attribution-NonCommercial 4.0 Uluslararası Lisansı altında lisanslanmıı̧tır.

Content of this journal is licensed under a Creative Commons Attribution-NonCommercial 4.0 International License. 


\section{INTRODUCTION}

According to Taffler and Tuckett (2011), the starting point of understanding investment behaviour is to accept that investment activities do not merely aim at maximising financial return as conventionally claimed, but have a much deeper meaning in unconscious reality. According to the emotional finance theory, unconscious processes play a key role in shaping individuals' financial decision-making. In this framework, and on the basis of psychoanalysis, emotional finance studies the role of unconscious mental processes in financial decision-making.

On the other hand, emotional finance claims that uncertainty dominates the markets. Conventional finance theories examine individuals' behaviour on the axis of risk and return. In essence, the concepts of risk and uncertainty are different from each other. According to Knight (1921) the fundamental difference between risk and uncertainty is that while the possible outcomes and probability of occurrence of an incident are known in the case of risk, in the case of uncertainty possible outcomes are known, but not the probabilities. According to Tuckett (2012), investors clearly face "radical uncertainty" and informational convergence. Tuckett and Nikolic (2017) indicated that the concept of radical uncertainty denotes circumstances where the outcomes of actions are ambiguous, it is difficult to establish the structure of the problem to choose between alternatives, and it is impossible to comprehensively represent the future.

Emotional finance utilizes concepts such as narrative, group feel, states of mind, and phantastic object to explain the unconscious behaviour of investors operating in a market where uncertainty holds sway. In the article, first of all, these concepts will be explained in depth and then the studies and findings in the field will be discussed.

\section{BASIC CONCEPTS OF EMOTIONAL FINANCE}

\subsection{Narratives}

Story denotes the oral/written telling of an event. Narratives started to find a place for themselves in the literature of finance with the emotional finance approach. According to Shiller (2017), although all disciplines started to make wider use of narratives especially since 2010, work carried out on narratives in the field of economy and finance make up not even 5 percent of all studies.

According to emotional finance, individuals who must make decisions under uncertainty create narratives to picture this uncertainty. The function assumed by narratives in this context is, in a sense, to make sense of uncertainty (Dumanlı \& Aren, 2019). Narratives constitute a natural human process that helps humans make sense of their lives and shape their experiences (Bruner, 1991). They enable us to construct events and their meaning in day-to-day life together with their causal effects (Tuckett \& Nikolic, 2017). According to Ochs and Capps (1996), narratives bring independent events together, establish a relationship between the past, the present and the imaginary future, socialise emotion, conduct and identity, and make the individual a member of the society. From a finance perspective, through narratives investors make sense of the uncertainty in which they find themselves, and feel that the unmanageable future can be managed and controlled to a certain degree (Eshraghi \& Taffler, 2015).

Chong and Tuckett (2015), on the other hand, suggest that emergence of feelings of both concern for loss and excitement for return is inevitable when individuals face situations with unforeseeable outcomes, and that participants manage the emotional conflicts in question through the construction of narratives. Nyman (2015) indicates that individuals make decisions by creating narratives that form an adequate opinion regarding potential returns while repressing anxiety and their suspicions of potential loss, and act accordingly. Narratives, while enabling one to make sense of the prevailing uncertainty, end the conflict between the emotions of anxiety and excitement. They help individuals take action, and continue their commitment to such action.

Another important function of narratives is that individuals construct an identity and legitimise such identity through narratives. According to Baumeister and Newman (1994), the individual's creation of a narrative about themselves is an important tool for others to recognise and approve this claim of identity. This way, the individual will have legitimised their identity. Similarly, emotional finance argues that investors make use of narratives in order to legitimise their investment decisions. Tuckett and Taffler (2012) and Esraghi and Taffler (2015) demonstrated that fund managers resort to narratives to legitimise the investment decisions they make (it is seen that fund managers create narratives in which they identify themselves as "heroes" when they succeed in their investments and as "victims" when they fail).

According to Dumanlı and Aren (2019), who summarise the role narratives play in emotional finance (Figure 1); narratives, while making sense of uncertainty to render it manageable, eliminate emotional conflicts. They thereby enable individuals to take action and remain committed to such action. Investors resort to narratives in order to legitimise their investment decision both within itself and in its social context.

The Conviction Narrative Theory (CNT), which strives to explain how individuals, through narratives, 
Figure 1. The Role of Narratives in Emotional Finance

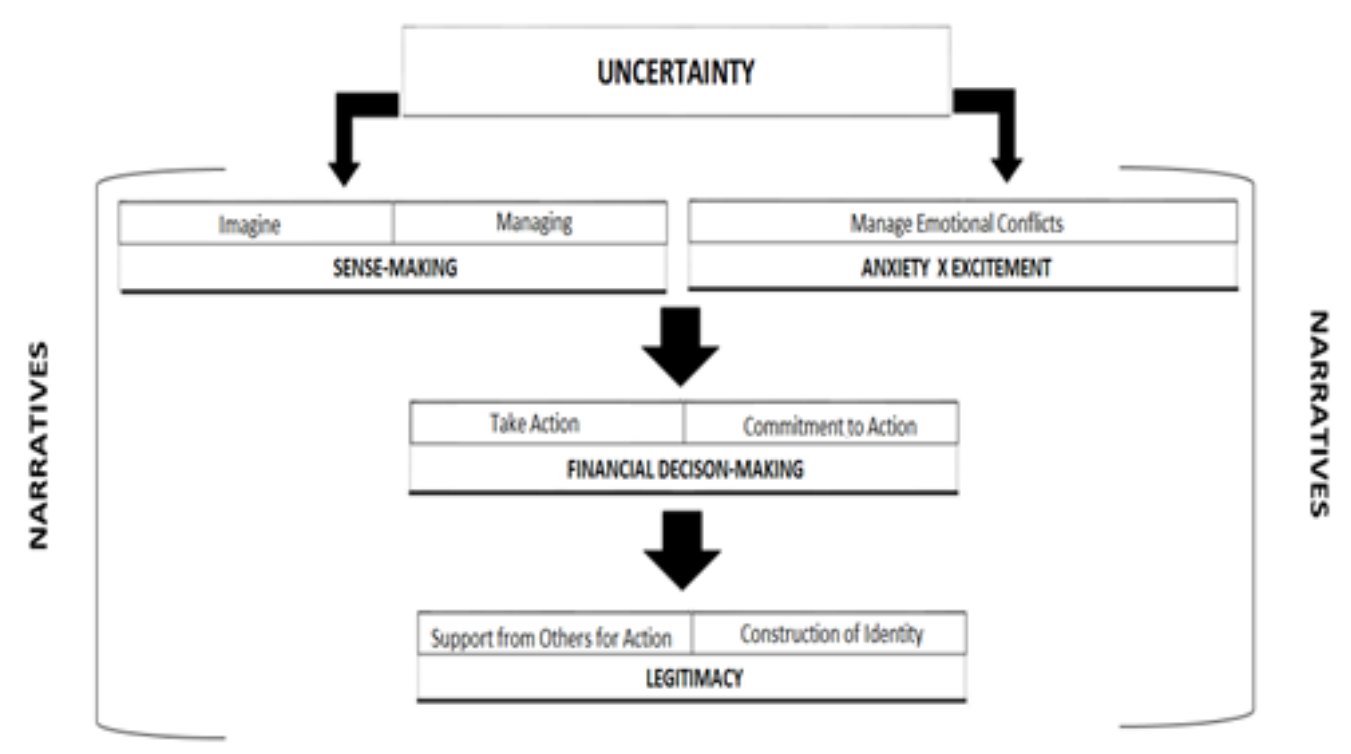

Source: Dumanlı \& Aren (2019), "Role of Narratives in Financial Decision Making from Perspective of Emotional Finance

make decisions under uncertainty and how they remain committed to such decisions, was born of studies examining the effect of narratives on financial decision-making. Nyman (2015) defines the CNT as a theory that aims at understanding and explaining how individuals make decisions under circumstances where optimal choices cannot be made. Conviction denotes "belief" and "sentence". According to the theory, individuals have a strong belief in narratives, and become enthralled by them. Tuckett and Nikolic (2017) claim that narratives, while enabling individuals to make sense of their circumstances, simulate the probable future outcomes of actions, and establish communication to receive support in their social context with respect to their actions, also make commitment to the action possible even in the case of a risk of loss.

The CNTs are created in interaction with other financial actors. Shiller (2017) said that narratives are "viral", that they appear randomly just as in organisms in evolutionary biology, and that, when contagious, the mutated narratives would cause unpredictable changes in the economy. Considering that numerous social media platforms such as Facebook and Twitter are now being used actively by millions of users, these findings are considerably accurate in today's world. Stories regarding financial products or markets are created collectively on such social channels, and influence masses (Dumanlı \& Aren, 2019).

\subsection{Group Feel}

The concept of group feel is different from the "groupthink", a concept in social sciences that attempts to explain the causes of collective behaviour, and the concept of "herding behaviour" in behavioural finance. Although all of these concepts attempt to offer explanations on the causes and effects of collective behaviour, they fail to provide an adequate explanation on the psychological and emotional reasons underlying such behaviour. Before explaining the concept of group feel, it will be useful to explain the concepts of groupthink and herding behaviour.

Janis (1971, quoted by Griffin, 2012) defines groupthink as the manner of thinking employed by people when they are deeply involved in a group. The members' efforts to reach a consensus override their motivation to realistically assess alternative types of action. Groupthink requires the members to share a strong "sense of solidarity", and to maintain the relations within the group at any cost. According to Hart (1991), group members' ascribing the utmost value to the group causes them to strive for a quick and painless unanimity on subjects the group must face. Personal doubts are repressed, the opposition is silenced, and the group leader's suggestions are accepted for the sake of protecting the social environment. According to McCauley (1998), Janis' groupthink concept is the theory of how the group dynamic intervenes on the path to making an optimal decision. The groupthink theory, while laying down the causes for the collective making of wrong decisions, ignores the emotional and mental conditions of individuals.

In finance literature, the study of the impact of group processes on investment decisions started in the 1970s, with the development of the behavioural finance literature. Conventional finance theories ignore the fact 
that market participants are socially included in an environment that affects their decisions and choices. On the other hand according to Fenzl \& Pelzman (2012), individuals within social dynamics may adjust their economic behaviour according to the choices and decisions of their associates, families and others.

The concept which behavioural finance uses when explaining group processes is herding behaviour. Blasco et al. (2012) defines herding behaviour as the situation in which investors, rather than acting on their own beliefs and knowledge, choose to imitate the practices of those who they believe to be more knowledgeable. According to Prechter and Parker (2007, quoted by Fenzl \& Pelzman, 2012), an increase in uncertainty gives rise to the emergence of unconscious herding impulses among market participants. Blasco et al. (2012) claimed that the fundamental cause that pushes individuals to herding behaviour is information asymmetry. Herding behaviour has been studied in many works in connection with individual investors as well as with corporate investors (Scharfstein \& Stein, 1990, Javaira \& Hassan, 2015, Fenzl \& Pelzman 2012), and it was suggested that there are various causes for corporate investors to engage in herding behaviour. According to researchs, the reasons for herding behaviour in professional investors may be reputation costs, pricing based on benchmark performance, etc.

In light of the studies on both groupthink and herding behaviour (Griffin, 2012, Hart, 1991, McCauley, 1998, Fenzl \& Pelzman,2012, Blasco et al.,2012), it is seen that these approaches indicate that individuals exist within a social environment and make decisions in communication with such environment. Both approaches, while offering various explanations regarding individuals' collective decision-making processes, fail to focus on the role of emotions in group processes. Emotional finance approaches group processes from the point of view of psychoanalysis and, in addition to considering the reasons for individuals' participation in groups, also attempts to explain the group's collective mood and its impact on the market.

Emotional finance uses the term group feel instead of groupthink. Group feel is a situation in which a group of individuals, based on a strong and unconscious foundation, directs their thoughts and behaviour to each other in order to not be different and to feel identical with the rest of the group (Tuckett, 2011). The point that is of interest in this definition is that such behaviour engaged in by the individuals is unconscious. Both the groupthink and the herding behaviour models consider the choices made by the individual and their desire to be part of the herd as conscious acts.

The group feel concept was based on Bion's works. According to Bion (1952, quoted by Tuckett, 2011), the existence of a group is different from gathering of in- dividuals. Being in a group means a reduction in individuality.

Bion makes a distinction between a work group and a basic assumption group that are the two main group processes, which demonstrate very different behaviour. According to Bion (1952, quoted by Taffler, 2014), in a work group members cooperate in a creative manner for a common purpose by using both positive and negative information in a suitable manner. On the other hand, when the basic assumption group acts, the purpose of the group is to provide its members with good emotions by means of unconscious defences. The group's existence is accepted for the sake of combating anxiety rather than working together on a thought based on reality and for a common purpose. Under such circumstances the group does not take the facts into consideration. According to Bion (1962, quoted by Tuckett \& Taffler, 2008), the behaviour of these groups towards information is also different. While information is used to perceive real events in the work group, it is used to make individuals feel good in the basic assumption group.

Conventional finance theory considers markets to be consisting of individuals acting independently from each other. This is the characteristic of the work group. However, financial markets often resemble large basic assumption groups that move away from individuality in their actions (Tuckett \& Taffler, 2008). According to the emotional finance theory, the market becomes a basic assumption group especially in the cases of asset pricing bubbles or financial crises.

According to Tuckett (2011), humans' process of processing information is not atomistic; it does not take place in an isolated setting, and the judgments made, the emotions experienced and the behaviour displayed exist within a social and psychological context. In order to understand investor behaviour, asset pricing bubbles and financial crises, one must not ignore the fact that humans are social beings. The group feel concept suggests that individuals, rather than based on their conscious choices, demonstrate a collective attitude on an unconscious basis in order to not be different and to generate good feeling. The point that requires attention here is that the market "unconsciously" becomes a basic assumption group (Tuckett, 2011). This point brings us to "states of mind", another important building block of emotional finance.

\subsection{States of Mind}

Klein (1935, quoted by Tuckett \& Taffler, 2012) defines two fundamental states of mind: The divided state of mind (DS) and the integrated state of mind (IS). In an IS individuals see the world as it is, as a whole with its good and bad features. In the DS, however, they mentally separate good and bad feelings to live in a black 
and white world where the discomfort of coping with the undesired reality is prevented (Bellotti et al. 2010). The IS is characterised by an awareness of multiple ideas that are to a certain extent connected. Here the individual may harbour opposing emotions, and may tolerate them without having to eliminate the potentially painful feelings created by conflict. The contradictions are felt and recognised, and uncertainty is accepted. It is accepted that an asset may have both good and bad qualities, and that it may both reward and disappoint us (Tuckett \& Taffler, 2012). In DS, however, conflicting representations of relations directed to an object exist in the mind, but these have not been consciously experienced, and are therefore not suitable for thinking - that is, not all relations are conscious. In the DS, a relation may unpredictably progress from love to hate or from hate to love. Reality is not perceived objectively, but is twisted - conflicting perceptions that may cause anxiety or disappointment are separated from the conscious. In short; situations that may cause anxiety or disappointment "are not thought" (Tuckett, 2011). The DS is "unconscious".

According to Klein $(1935,1946$, quoted by Taffler et al., 2017), in the DS, individuals make use of unconscious avoidance strategies or defence mechanisms to protect themselves against anxiety. Many defence mechanisms such as splitting, projection, denial, repression, displacement etc. have been identified. According to Cramer (1991), there is a general consensus in the literature that the objective of all of these defence mechanisms is to prevent the ego from degenerating or disintegrating due to excessive negative effects such as anxiety or guilt. According to Cramer (1991), if the objective of these defences is to deceive the ego in order to protect it, such deception can only be effective when the individual is unaware of its emergence, that is, if the defence is unconscious.

Another important question that must be asked here is what gives rise to defence mechanisms. According to Hentschel et al. (2004), while defence mechanisms may stem from emotions such as anxiety, shame, disappointment or guilt, they may also originate from threats to the individual's understanding of individuality such as social evaluation (being criticised by others) or a challenge to the personality traits that are found at the core of an individual's expression of their ego.

Investment decisions give rise to the emotions of excitement and anxiety. There is excitement and hope regarding the increase of the asset's price. The price may also drop, however, and this gives rise to anxiety. Since emotions that create excitement and anxiety are generated simultaneously, subjectively this leads to painful emotional conflict or ambivalence. Defence mechanisms step in to eliminate this conflict (Taffler, 2018). The defence mechanisms in question arise not only in individual investors, but also in the case of pro- fessional investors. Professional investors, in addition to facing the anxiety created by the investment decision, work under conditions that would cause anxiety, such as the peril of low performance that would lead to a loss of clients, the danger of losing their job if they fail to perform above the benchmark, and the pressure of being "exceptional" in the eyes of their clients and employers. In the interviews they held with fund managers, Tuckett and Taffler (2012, quoted by Taffler, 2018) found that the fundamental motivation while making investments was not greed, but a search for excitement, and the desire to discover the "perfect" investment. From this point of view, it can be said that the defence mechanisms observed in professional investors stem from emotions such as anxiety and shame, or threats such as a challenge to their personality traits.

In the emotional finance approach, splitting (mentally separating good and bad feelings, repressing bad feelings and rendering them unconscious), projection (unconsciously ascribing undesired emotions to others) and denial (the individual's denial of the aspects of reality they do not wish to know in order to reduce or prevent the painful effects related to the reality) are very prominent in individuals who are in a DS (Auchincloss \& Samberg, 2012, quoted by Taffler, 2014).

The concepts of defence mechanisms and states of mind not only help understand the investment decisions made by individual and professional investors, but also shed light on periods during which asset pricing bubbles inflate and burst. According to Tuckett and Taffler (2008), we face two questions, which conventional finance theory has difficulty in explaining, in connection with asset pricing bubbles. The first is, why are most of the economic agents unable to assess the creation of a bubble by using suitable financial information? The second question is, why do anger, blaming and scapegoating rather than a feeling of guilt emerge following all these events? Emotional finance answers these two questions using the concept of states of mind.

According to Tuckett (2011), in the DS conflicting emotions towards human beings or objects turn into completely-split love and hate relationships. Individuals or objects are hated without considering that they may be loved in the future. In the DS, the positive or negative qualities of the individual or the object are exaggerated. In this state, one is aware only of the love for the object (or individual) for its extraordinary qualities or of the hatred towards it for its perceived serious flaws.

Exaggerating the positive qualities of assets or hating them by foregrounding their negative qualities brings to mind the asset pricing bubbles in financial markets. In light of the definitions of DS and IS, the market actors in asset pricing bubbles are in a "divided mind" 
structure. Everything that may give rise to suspicion and concern are ignored, and individuals feel omnipotent (Tuckett \& Taffler, 2012). According to Tuckett and Taffler (2008), the information individuals possess to evaluate or price investment risks do not change during asset pricing bubbles. What changes is the mind's attitude towards the existing information. What creates and maintains the divided state of mind in asset pricing bubbles is narratives and group feel.

The group feel encountered in asset pricing bubbles may also be evaluated within the framework of states of mind. The distinction Bion (1952, quoted by Taffler, 2018) made between two group processes he referred to as the basic assumption group and the work group is essentially based on states of mind. While the basic assumption group acts within the scope of the DS, the features of the work group reflect the characteristics of the IS. According to Taffler (2018), in a work group members cooperate in a creative manner for a common purpose by using both positive and negative information in a suitable manner. However, in the basic assumption group the members provide the group's members with positive feelings through unconscious defences. In asset pricing bubbles, the market becomes a basic assumption group. Through the effect of the divided state of mind and the unconscious defence mechanisms, the group drifts away from reality. According to Taffler (2014), in the DS information is used to ensure comfort and encourage excitement. Emotions relating to the fact that the unforeseeable future cannot be controlled are mentally split, rejected and repressed through the basic assumption group thought in the market. This way the entire market, unconsciously and as a basic assumption group acting in a DS, starts believing that it is possible to do something which is very difficult, even if not impossible (Taffler, 2018).

In summary, the unpredictability of future returns, while not consciously recognised, determine investment activities and have psychological impacts (Taffler, 2018). Unpredictability may cause significant anxiety to the degree of giving rise to panic and desperation. Therefore, individuals make use of defence mechanisms to protect themselves against the fact that the future is uncertain, and to cope with the anxiety this may trigger (Taffler et al., 2017). Excitement and short-term rewards prevail, and precautionary measures are relaxed. According to Tuckett (2011), since reality is unconsciously split from the experience, this state of mind may continue for a while, but will inevitably collapse eventually. These explanations describe the creation and collapse of asset pricing bubbles in the financial markets. Curiosity and inadequate research are in the nature of asset price bubbles. The DS prevails, and there is an obvious corruption in the sense of reality. Therefore, the states of mind in which investment decisions are made must be studied as an important variable for understanding both investor behaviour and the emergence of asset pricing bubbles.

\subsection{Phantastic Object}

The investment process means that an investor engages in an ambivalent emotional relationship with something that can easily let them down (Taffler \& Tuckett, 2011). In other words, investors are required to establish an "object relation" with their investments.

Greenberg and Mitchell (1983, quoted by Huprich \& Greenberg, 2003) define object relation as "an individual's interaction with real and imaginary individuals/objects, and the relationship between their inner/ external object worlds". Tuckett (2011) emphasises the emotional attachment and relationship of attraction established with the object in the mind. Taffler et al. (2017), on the other hand, point out that it exists since birth, and creates the emotions of both excitement and anxiety mostly in an unconscious manner. In summary, object relations are ambivalent by nature, and their emotional reflections are contradictory.

Here, the concept of object is based on Freud's definition of object. This concept is used to identify the "representations" of individuals, ideas, or objects in our unconscious mind and imagination (Auchincloss \& Samberg, 2012, quoted by Taffler, 2018). What is meant by representation is image. According to Eshraghi and Taffler (2012), if what we refer to as object points at an image, the same object may have multiple versions in the minds of different individuals.

From a psychoanalytic point of view, the purchase and sale of assets require that imaginary object relations are established with them. In such case, imaginary relations aimed at creating or breaking emotional ties with the investment shall form part of the decisions to purchase, keep or sell (Tuckett \& Taffler, 2008).

What investors face in the market is not risk, but uncertainty. This circumstance gives rise to an anxiety that is mostly repressed. Considering the existence of such unbearable emotions, how can investors become engaged in bilateral object relations with assets that can easily cause them pain? Emotional finance explains this situation with the role of the sense of "trust" in the investment process (Taffler, 2018).

According to Taffler (2018), investment is not possible without trust. Trust suppresses concern and leads to action; from an emotional point of view it ties the present to the future - "creates" the desired future outcomes. Trust plays a key role in the resolution of anxiety, which is inherent in the investment process. To trust is to invest (Figure 2). 
Figure . 2 .

The Object Relation Established by The Investor

\begin{tabular}{|c|c|c|}
\hline \multirow{2}{*}{ INVESTOR } & Object Relation & INVESTMENT \\
\hline & Trust & INSTRUMENT \\
\hline
\end{tabular}

Akerlof and Shiller (2009) suggest that economists have actually been using the concept of trust in economic evaluations for a long time, but have been associating trust only with "prediction". According to them, since individuals are rational, they act on the basis of rational predictions. However, they emphasise that the word trust originates from "belief". The trusting person may not rationally evaluate the information they possess, and, even if they do, may not act in a rational manner. Actually, what is emphasised is that we make most of our decisions because "they feel right" to us. The question to be asked at this point is; what is the thing that constitutes the sense of trust, or, in Akerlof and Shiller's words, the belief underlying the sense of trust?

Emotional finance explains this process with "phantasy". Freud (1908, quoted by Spillius, 2001) refers to phantasy as the unconscious activity that fulfils the frustrated instinctive desires/wishes of an individual. According to Freud (1908, quoted by Spillius, 2001), the fundamental motive for the emergence of a phantasy is a desire, the fulfilment of which was prevented. Phantasy is a concealed expression and partial fulfilment of such desire.

Tuckett (2011) emphasises that phantasies are unconscious, and describes them as stories (emotion-intensive stories) we tell ourselves with respect to what we do with other individuals (objects) and what they do with us in our mind, of which we are only partially aware. Unconscious phantasy is similar to storytelling. It brings meaning to the experience and guides the subject to action. According to Taffler (2018), due to the mental processes subjected to repression, individuals cannot directly know their own or others' phantasies, and the implicit effects of these phantasies on conscious experiences or behaviour.

Accordingly, in a market in which they must decide under uncertainty, individuals' ability to establish an object relation with investment instruments depends on the existence of the sense of trust, and it is unconscious phantasies that create this sense of trust (Figure 3).

Figure 3. The Foundations of the Object Relation Established by The Investor

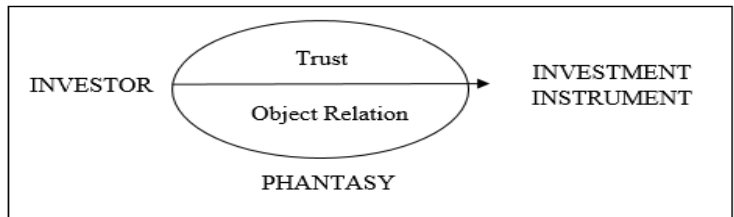

In the context of phantasy, the object has the potential of transforming into an extraordinary, exciting and desirable mental image (Taffler, 2018). According to Taffler et al. (2017), financial markets provide a setting where such phantasies may easily emerge. In order to identify attractive "objects" (financial assets) that cause excitement and the desire to idealise and therefore to possess, emotional finance brings together the concepts of object relations and unconscious phantasy (Tuckett \& Taffler, 2012), and defines such financial assets as "phantastic objects".

When investors establish an object relation with investment instruments that is dominated by phantasy, such investment instruments are referred to as "phantastic objects". A phantastic object corresponds to the object, or its reflection/ equivalent in the individual's mind, that completely fulfils the individual's deepest desires at the time and in the way the individual wants (Tuckett \& Taffler, 2008). The emergence of the phantastic object has been shown in Figure 4.

Figure 4. An Investment Instrument That Becomes a Phantastic Object

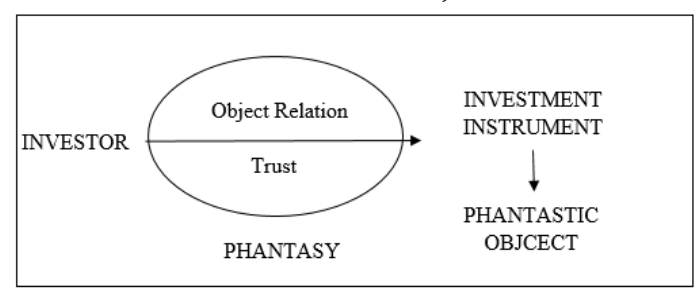

Phantastic objects are strong psychological sources of attraction that rouse phantasies related to pleasure or disappointment, and that act outside the conscious. They are, by nature, exciting and transformative (causing change), violate the rules of "normal" life, and "ransack 'normal' reality" (Tuckett \& Taffler, 2008).

The imaginary outcomes of the investment activity rouse the emotions of excitement for probable returns and anxiety for probable loss. In a sense, investment involves an unconscious hope that finding and possessing phantastic objects can be possible (Tuckett \& Taffler, 2012). In connection with phantastic objects, the investor's mind is dominated by the thought that a return that is very difficult, even if not impossible, is probable.

The emergence of phantastic objects and their domination of the market are closely related to the concepts of narratives, group feel and states of mind. In markets where phantastic objects exist, narratives, in addition to instilling meaning into uncertainty and rendering it manageable, eliminate emotional conflicts. This way, individuals take action and become committed to their actions. On the other hand, the concept of group feel suggest that individuals, rather than based on their 
conscious choices, demonstrate a collective attitude on an unconscious basis in order to not be different and to generate good feeling. Market participants which become a basic assumption group do not take heed of warnings. All kinds of questioning are prevented. In this process, individuals are in a DS. Through the effect of the DS and the unconscious defence mechanisms, the group drifts away from reality. Emotions relating to the fact that the future cannot be controlled are mentally split, rejected and repressed in the basic assumption group thought across the market. This way the entire market, unconsciously and as a basic assumption group acting in a DS, starts believing that it is possible to achieve a return which is very difficult, even if not impossible to achieve. With the simultaneous progress of these processes, the phantastic object starts to be perceived as real in individuals' minds. This process experienced by investors, who must take action under uncertainty, can be summarised as shown in Figure5.

Figure 5. The Emergence of Phantastic Objects According to Emotional Finance

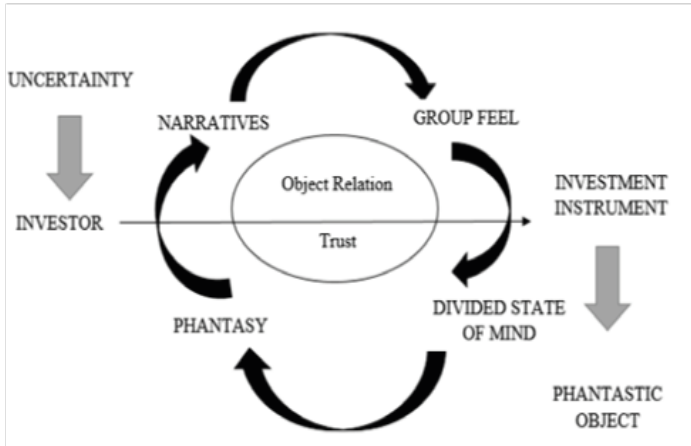

According to Taffler (2018), the emotional finance theory shows that all investments, not only in the context of asset pricing bubbles, but also under normal market conditions and day-to-day commercial operations, have the potential of becoming phantastic objects, and that investments trigger extreme emotions which transform love into hatred when they fail to perform as expected.

\section{STUDIES IN EMOTIONAL FINANCE}

Studies conducted in the field of emotional finance may be classified under two titles, namely studies tackling basic concepts and empirical studies. Whereas, empirical studies may be categorized as those conducted by in-depth interviews, relative sentiment shift analysis, and questionnaire method.

Conceptual studies tackle the four building stones of emotional finance which we had discussed in detail previously, and their correlation with one another. These studies are significant in order to enable understanding of the basic arguments in emotional finance.

In studies conducted by means of in-depth interview method in terms of empirical studies, mainly, data collected from the interviews held with fund managers who are professional investors were analyzed with the aim of revealing the correlation between the financial decision making process of fund managers and the basic concepts of emotional finance. These studies are important for providing support to the basic arguments discussed in the conceptual studies as well as for explaining such concepts in more concrete terms for finance researches by way of examples collected from interview data.

Taffler et.al. (2017) have conducted 51 in-depth interviews with fund managers and revealed what kind of anxiety was caused by the uncertainty in the investment process among the fund managers. According to the findings obtained from the research, fund managers work under significant pressure and, although they are aware of the fact that they cannot beat the market, they repress or ignore this situation in order to be able to continue with their works. This information accords with the defense mechanisms approach. They demonstrated the existence of splitting, projection and denial mechanisms.

Eshraghi and Taffler (2015) held interviews with 50 investment fund managers and a similar number of reports prepared for the investors by the fund managers have also been examined. The results demonstrate that fund managers use the narratives in order to justify their investment decisions from the viewpoint of their clients and employers. Both narrative sets use similar processes, one being verbal and unofficial and the other being written and official. While fund managers opt for narratives which might be classified as epic narratives where they depict themselves as heroes in the case of success of their investment decisions, they rather use tragic stories where they characterize themselves as victims if they are unsuccessful.

In their study, Chong and Tuckett (2015) conducted in-depth interviews with 52 fund managers. As a result of this study, "conviction narratives" concept has been coined. Having to decide under uncertainty, fund managers employ narratives in order to fight against the anxiety created by the uncertainty as well as to become exceptional in the eyes of their clients and employers, and these narratives go beyond being personal and become collective. Created in interaction with other financial actors, conviction narratives are used in a way to "simulate" imagined situations. Thus, a conviction emerges pertaining to the accuracy of the action. From this point of view, Chong and Tuckett (2015) assert that analyzing such narratives created in the market collectively may help elucidate the shifts occurring in the indicators such as GDP, etc.

In empirical studies, sentiment analysis has been conducted in unstructured data sets (news articles, resear- 
ch reports etc.) based on the data obtained by means of in-depth interview method. In the studies conducted by way of Relative Sentiment Shift Analysis (RSS) method, sentiment analysis was conducted in these data sets with a dictionary-based approach in order to detect the changes/shifts in sentiments in the course of time. RSS is important in terms of providing empirical support to the basic concepts of emotional finance.

Tuckket et.al. (2014) analyzed the articles published in Reuters about Fannie Mae, one of the important companies that went bankrupt during the 2008 crisis, and the e-mail data base of Enron, a company which was involved in a big scandal in 2001, in order to demonstrate whether or not the creation and development of phantastic objects may be monitored by way of narratives. As a result of the research, they revealed that it is possible to detect the emotional shifts in the narratives in the course of time and throughout social networks.

In their study, Tuckket et.al. (2015) created an RSS time series for American economy on the basis of data obtained from Thomson Reuters Archive. They conducted Granger causality tests to demonstrate whether or not there is a correlation between RSS and GDP growth rate and it was revealed that there is a correlation between RSS and GDP growth and RSS series can be used to forecast the GDP growth. Furthermore, when the RSS series that was formed is evaluated, it is observed that it provides early warning for the 2008 crisis.

In addition to the correlation between RSS series and GDP, Ormerod et.al. (2015) have also investigated the correlation between RSS series and Cleveland and St Louis Financial Stress Indices. It was identified that there is a relation of causality between the RSS series and the indices even though it is a weak one. In order to analyze this relation in further detail, they established a new RSS measure based on the word "liquidity" (where the words in the excitement and anxiety lists would be counted only if they appear in 100 characters on both sides of the word "liquidity") and they reexamined the correlation between this new RSS series and the indices. The correlation of the RSS series focused on the word "liquidity" is quite similar to the correlation of the general RSS series with the indices. However, this study is important in terms of demonstrating how the general RSS measure based on the number of the sentiment words can be changed and how it may be possible to further focus on the concepts that may be more directly related to the analyzed subject.

Nyman et.al. (2018) analyzed three unstructured data sources related to financial situation from the perspective of RSS: daily reports prepared by Bank of England on market news and events (MCDAILY), news articles published by Reuters in the United Kingdom (RTRS), and research reports prepared by brokers (BROKER). When RSS methodology is applied to these three se- parate data bases, it is observed that the RSS series produced have a common tendency. In particular, the RSS series produced from MCDAILY and RTRS reveal sharp declines before the 2008 financial crisis. On the other hand, it was investigated whether or not there is a correlation between these three RSS series and the variables, namely sentiment, trust and uncertainty. In this regard, Granger Causality Tests were applied in order to identify the correlation of these three RSS series with Michigan Consumer Sentiment Index, VIX Volatility Index, Economic Policy Uncertainty Index, Bank of England Macroeconomic Uncertainty Index, CDS premium and PMI Index and the leading and lagging correlations between the RSS Series and the financial and economic indicators were investigated. It was demonstrated that the three RSS series have considerably high correlation with the indicators in question.

There is only one study conducted by questionnaire method in the field of emotional finance. As a result of this study, a measure for emotional finance has been developed for the first time. Measures for phantasy and the determinants of phantasy were developed in the study performed by Aren and Nayman (2020). Measures were developed for narrative, divided state of mind, group feel, informed herding, uninformed herding, and phantasy, and furthermore, the capability of these determinants to describe phantasy was researched. It was demonstrated that divided state of mind affects phantasy directly, while group feel and narrative are indirectly affected by the informed herding. It was found out that the variables that direct the investment choices of individuals in the periods when asset pricing bubbles are formed are phantasy, group feel, uninformed herding, and divided state of mind.

When the studies conducted in the field are evaluated, it is observed that there is no detailed literature review on conceptual studies. The studies conducted by way of in-depth interview have been performed only with fund managers who are professional investors. The studies carried out with RSS methodology have focused generally on periods of crises or asset pricing bubble, leaving the studies aimed at normal market conditions limited. The study performed by way of questionnaire methodology is significant for introducing a measure to the literature.

\section{CONCLUSION AND EVALUATION}

Studies in the field of emotional finance gained further weight especially after the crisis of 2008. Attempts were made to explain the emergence and subsequent burst of asset pricing bubbles, which the conventional finance theory had difficulty in explaining, through the fundamental concepts of emotional finance. Also, in the context of asset pricing bubbles, analyses 
were conducted on why not only ordinary investors, but also professional fund

An important criticism that may be made here is that the studies which have been conducted mostly focus on the periods during which asset pricing bubbles and crises have occurred. In a manner similar to Fama's marginalisation of behavioural finance as "anomaly literature", the literature of emotional finance may also be criticised as being a "crisis literature".

Another criticism may be brought in connection with the problems relating to the practical application of the phantastic object approach suggested by emotional finance. It is difficult to detect asset pricing bubbles or financial crises during their emergence, or to identify when assets or investment instruments become phantastic objects under normal market conditions. Tuckett et al. (2014) suggested that the emergence and development of phantastic objects may be traced through narratives. The process of the emergence of narratives and the transformation of these narratives into phantastic objects in unstructured data sources has been demonstrated through the RSS. This analysis is different from sentiment analysis. Rather than categorising the emotions of a document or a set of documents in an absolute sense, it attempts to demonstrate the shifts that occur in emotions in time.

It is believed that the number of studies conducted on emotional finance will increase in the forthcoming periods in today's world where policy-makers have started to show great interest in monitoring financial stability following the latest crisis, and where analysing market participants' emotions towards assets or the market has become important. It is believed that especially new approaches such as monitoring the stories created by market participants in unstructured data sources and RSS aiming at using the changes that occur in emotions as precursors etc., if supported by machine learning-based approaches, may allow the early detection of potential phantastic objects and enable measures to be taken against bubbles or crises that may emerge.

There is limited work in the field of emotional finance, which has been conceptualized recently in finance literature. This study, which analyzes the concept of emotional finance in depth, makes an important contribution to the literature. Frequent financial bubbles and Ponzi schemes in recent years could not be predicted by both neoclassical finance and behavioral finance. People repeating the same mistakes and not learning lessons required different explanations. In this context, our study discusses in detail the concepts that can be considered new for finance literature such as narrative, group feel, states of mind, phantastic object. In this way, it provides awareness of both market makers and investors while shedding light on researchers. With this feature, our study makes a significant contribution to the literature. In further studies, it may be possible to provide support to the basic arguments involved in the conceptual studies by conducting in-depth interviews with individual investors, as well as to demonstrate the existence of different tendencies. Application of RSS methodology in normal market conditions will enable the model to be used as leading indicator. On the other hand, in addition to the general RSS, creation of new series based on more precise rules specific to the analyzed subject is promising in terms of forecasting basic macroeconomic indicators. Inclusion of RSS for general and specific purposes will enable increasing the description capability and reliability of the indices calculated for measuring financial stability. While the measure that is developed can be improved by adding factors thereto, such as personality characteristics etc., it will be also possible to demonstrate the aspects where individual investors and professional investors differentiate, by applying the said measure to professional investors. Moreover, it will be possible to reveal the cause-effect correlation between the newly added factors and basic concepts more clearly.

\section{REFERENCES}

- AKERLOF, G. \& SHILLER, R.J (2009). Animal Sprits, Scala Publications: İstanbul

- AREN, S. \& NAYMAN HAMAMCI, H. (2020), Emotional Finance: Determinants of Phantasy, Kybernetes, Vol. ahead-of-print No. ahead-ofprint. https://doi.org/10.1108/K-02-2020-0084

- BAUMEISTER, R. F. \& NEWMAN, L. S. (1994). How Stories Make Sense of Personal Experiences: Motives That Shape Autobiographical Narratives. Personality and Social Psychology Bulletin, 20(6), 676-690

- BellotTI, X. A., TAFfleR, R. J., \& Tian, L. (2010). Understanding the Chinese Stockmarket Bubble: The Role of Emotion. SSRN Electronic Journal. doi: 10.2139/ssrn.1695932

- BLASCO, N., CORREDOR, P., \& FERRERUELA, S. (2012). Does Herding Affect Volatility? Implications for the Spanish stock market. Quantitative Finance, 12(2), 311-327

- BRUNER, J. (1991). The Narrative Construction of Reality. Critical Inquiry, 18(1), 1-21

- CHONG, K. \& TUCKETT, D. (2015). Constructing Conviction Through Action and Narrative: How Money Managers Manage Uncertainty and The Consequence for Financial Market Functioning. Socio-Economic Review, 13(2), 309-330

- CRAMER, P. (1991). The Development of Defense Mechanisms. Theory, Research, and Assessment. New-York: Springer. 
- DUMANLI, A. N. \& AREN, S., (2019). The Role Of Narratives in Financial Decision Making: Narratives From The Perspective of Emotional Finance. 15TH International Strategic Management Conference, Poznan, Poland, 533-542.

- ESHRAGHI, A., \& TAFFLER, R. (2012). Hedge Funds and Unconscious Fantasy. Accounting, Auditing \& Accountability Journal, 25(8), 1244-1265.

- ESHRAGHI, A. \& TAFFLER, R. (2015). Heroes and Victims: Fund Manager Sensemaking, Self-Legitimation and Storytelling. Accounting and Business Research, 45 (6-7), 691-714.

- FENZL, T. \& PELZMANN L. (2012). Psychological and Social Forces Behind Aggregate Financial Market Behavior. Journal of Behavioral Finance, 13(1), 56-65

- GRIFFIN, E.M. (2012). A First Look At Communication Theory. Published by McGraw-Hill, Eighth Edition

- HART, P. (1991). Irving L. Janis Victims of Groupthink. Political Psychology, 12(2), 247.

- HENTSCHEL, U., SMITH, G., DRAGUNS, J.G. \& EHLERS, W. (2004). Defense Mechanisms in the Clinic, the Laboratory, and the Social World: Toward Closing the Gaps, Elsevier B.V.

- HUPRICH, S. K., \& GREENBERG, R. P. (2003). Advances in the Assessment of Object Relations in the 1990s. Clinical Psychology Review, 23(5), 665-698.

- JAVAIRA, Z., \& HASSAN, A. (2015). An examination of herding behavior in Pakistani stock market. International Journal of Emerging Markets, 10(3), 474-490.

- $\quad$ KNIGHT, F. H., (1921). Risk, Uncertainty and Profit. Boston: Houghton Mifflin.

- MCCAUley, C. (1998). Group Dynamics in Janis's Theory of Groupthink: Backward and Forward. Organizational Behavior And Human Decision Processes, 73(2-3), 142-162

- NYMAN, R. (2015). An Algorithmic Investigation of Conviction Narrative Theory: Applications in Business, Finance and Economics (Ph. D. Thesis). University College London, The Department of Computer Science.

- NYMAN, R., KAPADIA, S., TUCKETT, D., GREGORY, D., ORMEROD, P. \& SMITH,R. (2018). News and Narratives in Financial Systems: Exploiting Big Data for Systemic Risk Assessment. Bank of England, Staff Working Paper No.704

- OCHS, E. \& CAPPS, L. (1996). Narrating the Self. Annual Review of Anthropology, 25, 9-43.

- ORMEROD, P., NYMAN, R., \& TUCKETT, D. (2015). Measuring Financial Sentiment to Predict Financial Instability: A New Approach based on Text Analysis. arXiv: General Finance.
- SCHARFSTEIN, D. \& STEIN, J. (1990). Herd Behavior and Investment, The American Economic Review, 80 (3), 465-479.

- SHILlER, R. J. (2017). Narrative Economics. SSRN Electronic Journal, doi: 10.2139/ssrn.2896857

- SPILLIUS, E. B. (2001). Freud and Klein on the Concept of Phantasy. The International Journal of Psychoanalysis, 82(2), 361-373.

- TAFFLER, R. (2014). Emotional Finance: Theory and Application. WBS Working Paper

- TAFFLER, R. (2018). Emotional Finance: Investment and The Unconscious, The European Journal of Finance, 24 (7-8), 630-653

- TAFFLER, R. J., \& TUCKETT, D. A. (2011). Emotional Finance: The Role of The Unconscious in Financial Decisions. Behavioral Finance, 95-112.

- TAFFlER, R. J., SPENCE, C., \& ESHRAGHI, A. (2017). Emotional Economic Man: Calculation and Anxiety in Fund Management. Accounting, Organizations and Society, 61, 53-67.

- TUCKETT, D. (2011). Minding the Markets an Emotional Finance View of Financial Instability. UK: Palgrave Macmillan.

- $\quad$ TUCKETT, D., \& TAFFLER, R. (2008). Phantastic Objects and The Financial Market's Sense of Reality: A Psychoanalytic Contribution to The Understanding of Stock Market İnstability. The International Journal of Psychoanalysis, 89(2), 389-412

- TUCKETT, D. (2012). Financial Markets Are Markets in Stories: Some Possible Advantages of Using İnterviews to Supplement Existing Economic Data Sources. Journal of Economic Dynamics \& Control, 36, 1077 -1087

- $\quad$ TUCKETT, D. \& TAFFLER, R. (2012). Fund Management: An Emotional Finance Perspective. CFA Institute.

- TUCKETT, D., SMITH, R. E., \& NYMAN, R. (2014). Tracking Phantastic Objects: A Computer Algorithmic Investigation of Narrative Evolution in Unstructured Data Sources. Social Networks, 38, 121-133.

- TUCKETT, D., MANDEL, A., MANGALAGIU, D., ABRAMSON, A., HINKEL, J. (2015). Uncertainty, Decision Science, and Policy Making: A Manifesto for a Research Agenda. Critical Review: A Journal of Politics and Society, Taylor and Francis 2015, 27 (2), pp.213 - 242.

- TUCKETT, D. \& NIKOLIC,M. (2017). The Role of Conviction and Narrative in Decision-Making Under Radical Uncertainty. Theory \& Psychology, 27(4), 501-523. 